Original Article

\title{
Knowledge, Attitude and Practice about Diabetic Retinopathy among Medical Students
}

\author{
Shehla Dareshani ${ }^{1}$, Fiza Farooq ${ }^{2}$, Mir Amjad Ali $^{3}$, Nusrat Shah Khan ${ }^{4}$, Zaheer Sultan ${ }^{5}$ \\ ${ }_{1,2}$ Dow University of Health Sciences \& Civil Hospital, Karachi \\ ${ }^{3,4}$ Bilawal Medical College, Hyderabad, ${ }^{5}$ Dr. Ruth KM PFAU/Civil Hospital, Karachi
}

\begin{abstract}
Purpose: The study was conducted with the aim to decipher knowledge, attitude and practice of diabetic retinopathy among MBBS students of a medical college.

Study Design: A cross sectional survey.

Place and Duration of Study: Dow Medical College, from October 2019 to March 2020.

Methods: A cross sectional study was conducted among $3^{\text {rd }}$ and $4^{\text {th }}$ year medical students. A total of 133 students were questioned through specific questionnaire. After informed consent, demographic details were noted. Apart from source of information of students' knowledge, set of 14 questions were asked. In the first 7 questions information of knowledge of diabetic retinopathy was addressed. Four questions were about attitude and 3 regarding practice towards diabetic retinopathy. Windows MS Excel was used for quantitative and qualitative analysis.
\end{abstract}

Results: The mean of the overall KAP score for all students was $53.3 \pm 1.2$ (maximum, 70). Male students scored better in knowledge (24.8 vs 23.7$)$ and attitude (17.3 vs 16.5). Students scored poor in identifying correct values of $\mathrm{HbA} 1 \mathrm{c}$ and prevalence of diabetes in our country in the knowledge section. Students also lacked in identifying proper time of followup for screening of diabetic retinopathy. Many students thought uneducated people develop diabetic retinopathy earlier than educated.

Conclusion: Our study pointed out weakness in knowledge and practice of medical students regarding prevention and management of diabetic retinopathy. Proper training and teaching of students is required for improved management and counselling of diabetic retinopathy.

Key Words: Diabetic retinopathy Medical students

How to Cite this Article: Dareshani S, Farooq F, Ali MA, Khan NS, Sultan Z. Knowledge, Attitude and Practice about Diabetic Retinopathy among Medical Students. Pak J Ophthalmol. 2022, 38 (1): 71-75.

Doi: $10.36351 /$ pjo.v38i1.1299

\section{INTRODUCTION}

Diabetes is a non-communicable global crisis, which has become prevalent over the past years. Number of

Correspondence: Mir Amjad Ali

Bilawal Medical College, Hyderabad

Email: dramjad169@gmail.com

Received: June 14, 2021

Accepted: December 12, 2021 people with diabetes has increased from 108 million in 1980 to 422 million in 2014. ${ }^{1}$ In Middle East and North Africa every $10^{\text {th }}$ individual is suffering from diabetes. While is South East Asia half of the patients with diabetes remain undiagnosed. ${ }^{2}$ It is estimated that in developed world it will increase from 51 to 72 million meanwhile in the developing countries, a $170 \%$ rise is expected from 84 to 228 million by year $2025 .^{3}$ In Pakistan diabetes will rise to 11.6 million by $2025 .{ }^{4}$ Current prevalence of diabetes in Pakistan was $11.77 \% .^{5}$ 
Diabetes is associated with various complications related to micro vessels and nerves. Ocular pathology specifically retinopathy is an emerging diabetic complication. Around $35.6 \%$ of all diabetic patients have diabetic retinopathy. ${ }^{6}$ This has placed diabetes as the fourth leading cause of blindness. ${ }^{7}$ However, blindness associated with diabetes is avoidable and can be delayed with prompt detection and treatment.

Risk factors of diabetic retinopathy includes duration of diabetes, increasing age, and smoking. ${ }^{8}$ Other risk factors include hypertension, pregnancy and obesity. Type 1 diabetic patients are more prone to go blind from diabetic retinopathy. Wisconsin Epidemiologic Study of Diabetic Retinopathy (WESDR) showed that $3.6 \%$ of young patients (type 1 diabetes) and $1.6 \%$ of older (type 2 diabetes) lost their vision. ${ }^{9}$ Duration of diabetes is a good demarcation of the progression of diabetic retinopathy. Twenty five percent of type-I diabetics have retinopathy after 5 years of diagnosis, $60 \%$ develop after 10 years, and $80 \%$ after 15 years. ${ }^{10}$ Early screening of diabetes assists in treatment protocols. According to American Academy of Ophthalmology first fundus examination in Type 1 should be done 3 - 5 years after diagnosis and in Type 2 immediately after diagnosis. ${ }^{11}$

Pan retinal photocoagulation PRP can reduce risk of vision loss to $<2 \%$ for severe non-proliferative and proliferative retinopathy according to Early Treatment of Diabetic Retinopathy Study (ETDRS). ${ }^{12}$ Early vitrectomy has benefit in very severe PDR as it improves visual acuity to $6 / 12$ or better after vitrectomy. ${ }^{13}$ Anti VEGF has shown promising results in patients with macular edema.

Glycosylated hemoglobin (HbA1c) levels are tested for glycemic status in diabetes mellitus. The optimal cutoff value of $\mathrm{HbA} 1 \mathrm{c}$ for diabetic in Pakistan is taken as $<6.05 \% .{ }^{14}$ Prevention and treatment of diabetic retinopathy needs multi-disciplinary approach. Cooperation from community level and participation of practitioner together play important role.

This study was therefore carried to evaluate knowledge, practice and attitude of medical students regarding diabetic retinopathy. Their knowledge was addressed by the understanding that they had about diabetic retinopathy as a complication of diabetes. Attitude was perceived as their own ideas and feelings while practices are the ways that they put knowledge and attitude together to implement actions.

\section{METHODS}

A cross sectional study was conducted amongst $3^{\text {rd }}$ and $4^{\text {th }}$ year medical students of Dow Medical College who rotated in Ophthalmology Department from October 2019 to March 2020 during their clinical rotation. Owing to ethical considerations permission was obtained from institutional review board. Confidentiality of the data was maintained at all levels. A total of 133 students were questioned through specific questionnaire. After informed consent, demographic details were noted. Apart from source of information of students' knowledge, set of 14 questions were asked. In the first 7 questions information of knowledge of diabetic retinopathy was addressed. Four questions were about attitude and 3 regarding practice towards diabetic retinopathy.

Table 1: Questionnaire.

\begin{tabular}{|c|c|c|}
\hline \multicolumn{3}{|l|}{ What is normal HbA1c level? } \\
\hline \multicolumn{3}{|l|}{ What is prevalence of diabetes in Pakistan? } \\
\hline \multicolumn{3}{|l|}{ What are the risk factors of diabetes? } \\
\hline \multicolumn{3}{|l|}{$\begin{array}{l}\text { What are the symptoms of diabetic } \\
\text { retinopathy? }\end{array}$} \\
\hline Which diabetics are at greater risk of DR? & Type 1 & Type 2 \\
\hline $\begin{array}{l}\text { Control of diabetes is important in } \\
\text { prevention of DR? }\end{array}$ & Yes & No \\
\hline $\begin{array}{l}\text { Duration of diabetes is important in } \\
\text { prevention of DR? }\end{array}$ & Yes & No \\
\hline Visual loss due to DR can be prevented? & Yes & No \\
\hline More uneducated people develop DR? & Yes & No \\
\hline Routine examination is must for all DR? & Yes & No \\
\hline Early detection can prevent visual loss? & Yes & No \\
\hline \multicolumn{3}{|l|}{ What are the treatment options for DR? } \\
\hline \multicolumn{3}{|l|}{ What advice will you give to the patients? } \\
\hline \multicolumn{3}{|l|}{$\begin{array}{l}\text { How often should diabetic visit } \\
\text { ophthalmologist? }\end{array}$} \\
\hline What advice will you give to patients? & & \\
\hline
\end{tabular}

The knowledge questions were assigned marks according to the answers. Each correct answer was rewarded 5 marks and 0 if the person was unaware or gave wrong answer. While questions regarding attitude were asked with option of yes or no. Cumulative marks of questions related to knowledge, attitude and practice were classified into 3 groups. Excellent response was $75-100 \%$, fair was $50-74 \%$ and 0 to $49 \%$ was poor. ${ }^{15}$ Data was collected and analyzed and coded via Windows MS Excel. Graphical analysis was used for qualitative data while mean and standard deviation was calculated for quantitative data. 


\section{RESULTS}

A total of 133 students were questioned from $5^{\text {th }}$ semester to $8^{\text {th }}$ semester. Mean age of the students were $21.3 \pm 1.3$ years. Among 133 students $18 \%$ were male and $82 \%$ were females. Further details are found in Table 2.

Table 2: semester distribution and education of diabetic retinopathy of medical students.

\begin{tabular}{lrc}
\hline Variables & $\mathbf{N}$ & $\mathbf{\%}$ \\
\hline Semester & & \\
$5^{\text {th }}$ & 19 & 14.3 \\
$6^{\text {th }}$ & 42 & 31.6 \\
$7^{\text {th }}$ & 33 & 24.8 \\
$8^{\text {th }}$ & 39 & 29.3 \\
Education about diabetic retinopathy acquired from & \\
Medical college education & 50 & 37.6 \\
Internet & 31 & 23.3 \\
Books and combination of sources & 38 & 28.6 \\
Journals and continued medical education & 14 & 10.5 \\
\hline
\end{tabular}

Regarding knowledge, $39.1 \%$ of the students did not have any idea regarding value of $\mathrm{HbAlc}$ and $36.8 \%$ gave wrong answer. Only 6\% answered correctly regarding prevalence of diabetes in Pakistan. Ninety seven percent students responded that duration of diabetes was important in developing diabetic retinopathy and $98.5 \%$ responded that control of diabetes was significant in prevention of diabetic retinopathy.

Symptoms and risk factors of diabetes were assessed by scoring. Majority of the students identified risk factors of diabetic retinopathy as uncontrolled diabetes. Variable other risk factors like obesity, smoking, hyperlipidemia and sedentary lifestyle were also recorded along with uncontrolled sugar levels. Ninety three percent reported that symptoms of diabetic retinopathy were blurred vision, vision loss and floaters and $52.6 \%$ students considered type 1 diabetes to be more associated with diabetic retinopathy than type 2 . Regarding attitude, $89.5 \%$ of the students considered that visual loss due to diabetes can be prevented and $95.5 \%$ responded that routine ophthalmic examination is must for all diabetic patients. Role of early detection of diabetes in preventing diabetic retinopathy was highlighted by $96.2 \%$ students. Seventy three percent students had the concept that diabetic retinopathy was more common in uneducated patients.

Ten percent students did not know about the time of followup for a diabetic patient and $46.6 \%$ responded that 6 months to 1 year was the followup time. Thirteen percent students were unable to give advice to the patients.

\section{Overall KAP Score}

The mean of the overall KAP score for all students was $53.3 \pm 1.2(76 \%)$. The knowledge score was 23.9 $\pm 1.77(68 \%)$, attitude score was $17.7 \pm 0.5(85 \%)$ and practice score was $11.7 \pm 0.65(78 \%)$.

The mean overall score for males $(54.66 \pm 4.04)$ was higher than for females $(53 \pm 3.86)$. The male students scored better in knowledge and attitude while females scored better in practice.

Table 3: Shows KAP Score by Gender.

\begin{tabular}{lcccc}
\hline Variables & \multicolumn{4}{c}{ Mean + SD } \\
Gender & $\begin{array}{c}\text { Knowledge } \\
\text { Maximum: }\end{array}$ & $\begin{array}{c}\text { Attitude } \\
\text { Maximum: }\end{array}$ & $\begin{array}{c}\text { Practice } \\
\text { Maximum: }\end{array}$ & $\begin{array}{c}\text { Total } \\
\text { Maximum: }\end{array}$ \\
& $\mathbf{3 5}$ & $\mathbf{2 0}$ & $\mathbf{1 5}$ & $\mathbf{7 0}$ \\
\hline Male & $24.8+5.0$ & $17.3+3.9$ & $12.5+3.2$ & $54.6+4.04$ \\
Female & $23.7+4.6$ & $16.5+3.6$ & $12.8+3.4$ & $53+3.86$ \\
P value & 0.15 & 0.12 & 0.34 & \\
\hline
\end{tabular}

\section{DISCUSSION}

Our results of study will help in establishing a uniform pathway to assist us in promoting methods of teaching amongst students in areas where they lag behind. Need for CME and encouraging students to read medical journals will be our proposed methods. Study is going to play important role in prevention of diabetic retinopathy in community too since these students are the first one to come in contact with patients in their teaching clinics.

Maximum KAP score in our study was $76 \%$. A similar study conducted in Pakistan found KAP score of more than $70 \% .{ }^{16}$ Our study revealed that knowledge information about diabetic retinopathy was good amongst students $68.5 \%$ (KAP: 23.9/35). Whereas study in Switzerland reported mediocre knowledge among their students. ${ }^{17}$ Majority of the students according to our study results were able to identify risk factors of diabetic retinopathy correctly like study of Odisha. ${ }^{18}$ Many of our students could not tell prevalence of diabetic retinopathy in Pakistan. This is in accordance with study conducted in Saudia where $40 \%$ did not know the prevalence. ${ }^{19}$

A positive attitude was found amongst our students as $95 \%$ believed that diabetes was preventable with early detection and therefore required routine 
ophthalmic assessment. It was similar to the study conducted in Odisha. ${ }^{18}$

Seventy four percent of students believed that diabetes was more prevalent among uneducated population. Such results have also been reported in a study at Saudia. ${ }^{19}$ This shows confusion prevailing among students regarding practice towards diabetes. Another study highlighted the salient reasons for low KAP status. It included a busy schedule, less resources, inadequate periodic training in eye care and absence of retinal evaluation training. ${ }^{20}$

Practice assessment revealed that our students lagged behind in this area. Only $8.6 \%$ students identified correct modalities of treatment of diabetic retinopathy like intravitreal injection, laser procedures and surgical procedures. A fair percentage was totally unaware of the idea that how frequent should be the followup be done by an ophthalmologist.

Limitations of this study are that we considered knowledge of $3^{\text {rd }}$ year students equal to the $4^{\text {th }}$ year students who have completed their ophthalmology teaching and clinical rotation by that time. Comparison between these two groups of students should also be done. It was a single center study and do not represent the overall picture of all our medical students.

\section{CONCLUSION}

Our study pointed out weakness in knowledge and practice of medical students regarding prevention and management of diabetic retinopathy. It also assisted us in deciphering common confusion faced by our students regarding treatment modalities. There is a dire need to conduct workshops and seminars to address the teaching modalities of our medical system. Special attention is required in teaching our young graduates to aid in treating this reversible cause of blindness prevailing in our society.

\section{Ethical Approval}

The study was approved by the Institutional review board/Ethical review board

(IRB-1296/DUHS/Approval/2021).

\section{Conflict of Interest}

Authors declared no conflict of interest.

\section{REFERENCES}

1. Diabetes. World Health Organization. Available at: https://www.who.int/nmh/publications/fact_sheet_diabe tes_en.pdf. Accessed 26 ${ }^{\text {th }}$ November 2021.

2. International Diabetes Federation. IDEF Diabetes Atlas. 6th ed. 2014 update. [Updated 2014. Cited 2014 Oct 20]. Geneva (CH): World Health Organization; 2014

3. King H, Aubert RE, Herman WH. Global burden of diabetes, 1995-2025: prevalence, numerical estimates, and projections. Diabetes Care, 1998; 21 (9): 14141431 .

4. Atlas II. 7th Edn. International Diabetes Federation, 2015.

5. Meo SA, Zia I, Bukhari IA, Arain SA. Type 2 diabetes mellitus in Pakistan: Current prevalence and future forecast. J Pak Med Assoc. 2016; 66 (12): 1637 1642. PMID: 27924966.

6. Yau JW, Rogers SL, Kawasaki R, Lamoureux EL, Kowalski JW, Bek T, et al. Global prevalence and major risk factors of diabetic retinopathy. Diabetes Care, 2012; 35: 556-564.

7. Tumosa N. Eye disease and the older diabetic. Clin Geriatr Med. 2008; 24: 515-527.

8. Gadkari SS, Maskati QB, Nayak BK. Prevalence of diabetic retinopathy in India: The all India ophthalmological society diabetic retinopathy eye screening study 2014. Indian J Ophthalmol. 2016; 64 (1): 38 .

9. Fong DS, Aiello L, Gardner TW, King GL, Blankenship G, Cavallerano JD, et al. Retinopathy in diabetes. Diabetes Care, 2004; 27 (Suppl. 1): s84-87.

10. Kanski JJ. Clinical ophthalmology: A systematic approach. $9^{\text {th }}$ edition. Butterworth Heinemann Elsevier, 2019.

11. American Academy of Ophthalmology Retina Panel: Preferred practice pattern guidelines: Available at: https://www.aao.org/preferred-practice-pattern/diabeticretinopathy-ppp Accessed 26th November 2021.

12. Early Treatment Diabetic Retinopathy Study Research Group: Early photocoagulation tor diabetic retinopathy (ETDRS report number 9). Ophthalmology, 1991; 98 (5 Suppl.): 766-785.

13. Diabetic Retinopathy Vitrectomy Study Research Group: Early vitrectomy for severe proliferative diabetic retinopathy in eyes with useful vision: results of a randomized trial (DRVS report number3). Ophthalmology, 1988; 95: 1307-1320.

14. Nida S, Khan DA, Ijaz A, Khan MQ, Aleef H, Abbasi M. Determination of Mean Glycated Haemoglobin in Healthy Adults of a Local Population. J Coll Physicians Surg Pak. 2017; 27 (7): 399-403.

15. Al-Wadani FA. Nursing Students Perceived Knowledge, Attitudes, and Practices concerning ocular complications of diabetes. Int J Innov Res Multidiscip Field, 2016; 2 (9): 119-128. 
16. Mumtaz S, Ashfaq T, Siddiqui H. knowledge of medical students regarding diabetes mellitus at Zia-udDin University, Karachi. J Pak Assoc. 2009; 59: 163166.

17. Roman Trepp, Tonio Wille, Thomas Wieland and Walter H. Reinhart Diabetes-related knowledge among medical and nursing house staff, Department of Internal Medicine, Kantonsspital Graubunden, Chur, Switzerland, Swiss Med WKLY. 2010; 140 (25-26): 370-375.

18. Panigrahi S, Sahu RK, Jali SN, Rath B, Pati S, Kerketta M. knowledge, attitude and practice regarding diabetic retinopathy among medical and nursing students of a tertiary care teaching hospital of Odisha: a cross sectional study. IOSR J Dent Med Sci. 2017; 16: 1-7.

19. Wadaani FA. The knowledge attitude and practice regarding diabetes and diabetic retinopathy among final year student of King Faisal University Medical College of Al-Hasa Region of Saudia Arabia a cross sectional survey, Niger J Clin Prac. 2013; 16 (2): 164-168.

20. Abu-Amara TB, Al Rashed WA, Khandekar R, Qabha HM, Alosaimi FM, Alshuwayrikh AA, et al. Knowledge, attitude and practice among nonophthalmic health care providers regarding eye management of diabetics in private sector of Riyadh, Saudi Arabia. BMC Health Serv Res. 2019; 19 (1): 375. Doi: 10.1186/s12913-019-4216-9.

\section{Author's Designation and Contribution}

Shehla Dareshani; Associate Professor: Concepts, Design, Literature Search, Data Acquisition, Data Analysis, Statistical Analysis, Manuscript Preparation, Manuscript Editing, Manuscript Review.

Fiza Farooq; Post Graduate Student: Design, Data Acquisition, Data Analysis, Statistical Analysis, Manuscript Review.

Dr. Mir Amjad Ali; Professor: Concepts, Design, Literature Search, Data Acquisition, Data Analysis, Statistical Analysis, Manuscript Preparation, Manuscript Editing, Manuscript Review.

Nusrat Shah Khan; Assistant Professor: Concepts, Design, Literature Search, Data Acquisition, Data Analysis, Statistical Analysis, Manuscript Preparation, Manuscript Editing, Manuscript Review.

Dr. Zaheer Sultan; Consultant Ophthalmologist: Concepts, Design, Literature Search, Data Acquisition, Data Analysis, Statistical Analysis, Manuscript Preparation, Manuscript Editing, Manuscript Review. 